\title{
The Problems of the Exploitation of Industry Technology Roadmap and the Implications of the Science Management of Local Government
}

\author{
Min Liu, Fugang Zhao \\ Guangdong Academy of Sciences, Guangzhou, China \\ Email: minzoe@126.com
}

Received 9 October 2015; accepted 8 November 2015; published 11 November 2015

Copyright (C) 2015 by authors and Scientific Research Publishing Inc.

This work is licensed under the Creative Commons Attribution International License (CC BY). http://creativecommons.org/licenses/by/4.0/

\section{(c) (i) Open Access}

\begin{abstract}
In recent years, there is a great concern about the research of industry technology roadmap in the area of domestic IA collaboration. The local government exploited the industry technology roadmap successively, planned and guided the development of regional industries by scientific methods. However, there are still some noticeable problems. This paper sorts out these problems systematically and tries to propose some implications of the science management of the local government.
\end{abstract}

Keywords

Industry Technology Roadmap, Exploitation Process, Local Government, Science Management

\section{Introduction}

Technology roadmap first appeared in the American automobile industry in the middle of the 20th century. For reducing cost the automobile industry urged the suppliers to provide their technology roadmap of their future products at that time which was the critical period for the American manufacturing industry to cut cost and enhance competiveness. Thus, the technology roadmap - a new tool for management-emerged as the times required. From the 1970s to the 1980s, Motorola and Corning successively used the technology roadmap in order to promote the investment decisions of the R\&D of the strategy technology and the product by analyzing the requirement about the development of the products and technology at the future and recognizing the important technical factors which might be ignored in the process of production. That was the first pattern of technology 
roadmap which was product technology roadmap. The major use of the product technology roadmap is to forecast the tendency of the technology development of the related industries. The exploitation of product technology roadmap, which is the important reference of the development of the industry, is participated by various kinds of the officer, production, study and research institutions, such as the government, enterprises, industry associations, alliances, universities, scientific research institutions, etc. The National Technology Roadmap for Semiconductor (NTRS) was the first industry technology roadmap, and the professors from Japan, Europe and South Korea participated in the process of the update of the NTRS, thus the NTRS was renamed as International Technology Roadmap for Semiconductor (ITRS) in 1998. In 2008, the senior staffs of the three major information industry associations from U.S. came to China to introduce the ITRS and invited China to become one of the members of the International Semiconductor Industry Committee to join their strategic system ${ }^{1}$. So we can say that the industry technology roadmap which has gathered global innovation resource has become an important tool of the science and innovation management.

In recent years, the author had participated in the exploitation process of some industry technology roadmaps. Furthermore, through the investigation and survey of the exploitation process of industry technology roadmap in some provinces and cities, the author found that many regions didn't make the roadmap play an important role, resulting in the effect of the roadmap decreased. The reason is that some important problems are ignored in the exploitation process of roadmap. This paper tries to sort out these problems systematically to improve the exploitation process of industry technology roadmap to promote its effects on the regional industry development.

\section{Literature Review of the Research about the Problems of the Exploitation Process of Industry Technology Roadmap}

In recent years, the development of the technology roadmap has attracted the intention of the academia and the industries of domestic and oversea. Not only has the exploitation process of technology roadmap been researched in depth, but also has the application value of the roadmap been embodied more.

\subsection{Foreign Researches about the Problems of the Exploitation Process of Industry Technology Roadmap}

The first person impelled the research of technology roadmap is the CEO of the Motorola and the first person described the technology roadmap in the academic journal ${ }^{2}$ is Willyard and McClees (1987). The technology roadmap research center of the Purdue University and the technology management center of the University of Cambridge accumulated abundant research experience of the industry technology roadmap. However, the literature about the problems of the exploitation process of technology roadmap is limited, especially about the problems of the exploitation process of industry technology roadmap. The main contribution of the Purdue University is to share the technologies researched and developed by the industry associations, research institutions and enterprises in the public network and to do the data mining, ontology study and dynamics analysis for different industry technology roadmaps [1]. The technology management center of the University of Cambridge focused on the exploitation and research of the product technology roadmaps of the SMEs and exploited the T-plan, a method of the exploitation of product technology roadmap. The Industry Canada exploited the industry technology roadmap based on the technology roadmap of U.S. and England. Furthermore, Kostoff and Schalle (2001) built a operability systematize tool based on text mining method to analyze breakthrough technologies, found the professors related to these technologies to bring them into the team of the exploitation of roadmap [2]. Gerdsri and Kocaoglu (2007) built a technology development envelope method to keep the vitality of the roadmap and integrated the AHP to the research framework to make the roadmap become dynamic, flexible and more operable [3]. Sungjoo et al. (2008) proposed an exploitation method of roadmap for the R\&D planning, applied the patent data to the quantitative analysis to exploit technology roadmap to form a reliable decision-making mechanism, and constructed patent analysis graphics for four hierarchic, actor-similarity map, actor-relation map, technology-industry map and portfolio-affinity map which were related to the hierarchic of the research, technology, product and market of the roadmap respectively [4]. Byungun et al. (2008) constructed the roadmap base on the text mining and morphology analysis [5]. The Australian department of industry proposed

\footnotetext{
${ }^{1}$ Refer to "Guangdong Province is the first to make the industry technology roadmap planning". http://www.most.gov.cn/dfkj/gd/zxdt/201009/t20100916 81985.htm

${ }^{2}$ Harles H. Willyard and Cherry W. McClees published paper "Motorola's technology roadmap process" in the Research Management.
} 
an exploitation template for industry technology roadmap (as Figure 1) after summarizing the different exploitation methods of industry technology roadmap of different countries [6].

Although there were four kinds of method - expert method (as Table 1), working team method, computer method and synthetic method [7] - summarize from the foreign practical experience, there were few people research about the detail questions should be focused in the exploitation process. Tong and Li (2011) pointed out there were still no research result about the question how the suggestions proposed in the interaction process between the experts in the seminars of the exploitation of technology roadmap extended and restrained to realize the qualitative to quantitative integration [1].

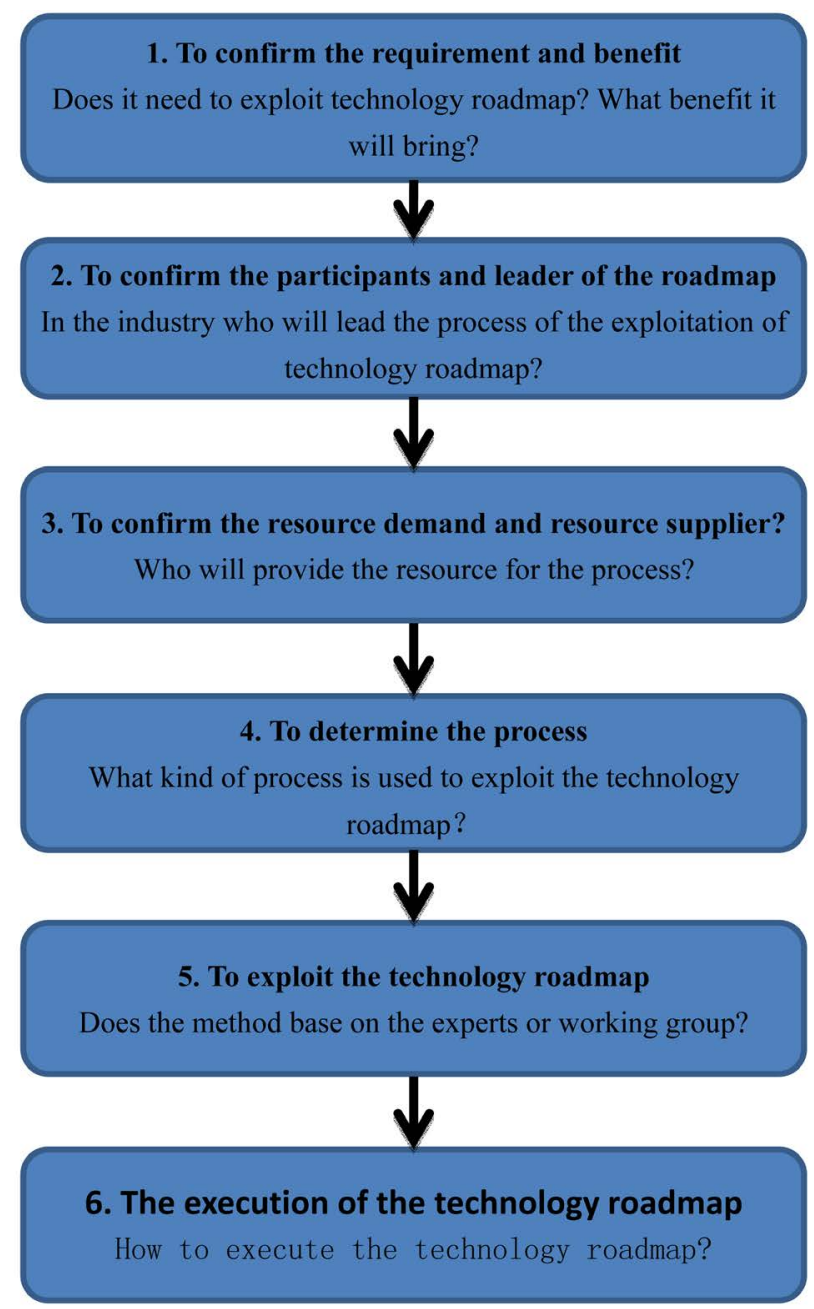

Figure 1. An exploitation template for industry technology roadmap proposed by the Australian Department of Industry. Data source: quote from Liu and Ke (2006).

Table 1. The exploitation method of the technology roadmap.

\begin{tabular}{|c|c|}
\hline Name & Characteristic \\
\hline Expert Method & To use the experts' knowledge to determine the factors \\
\hline Working Group Method & $\begin{array}{l}\text { The working group consist of persons with different ground } \\
\text { and use their experience to determine the factors }\end{array}$ \\
\hline Computer Method & To use the special software to manage all kinds of information, to confirm the factors \\
\hline Synthetic Method & Synthesize the Expert Method, Working Group Method and Computer Method \\
\hline
\end{tabular}

Data source: quote from http://www.panzhihua.gov.cn/ztzl/ftzd-kjzk/cyzc/jslxt/132996.shtml. 


\subsection{Domestic Researches about the Problems of the Exploitation Process of Industry Technology Roadmap}

The domestic research about industry technology roadmap has made large process in the recent years. The first person introduced the concept about technology roadmap is Li et al. $(2004,2005)$ from Tsinghua University [8] [9]. Thereafter, the domestic research on the roadmap mainly focused on three levels. 1) National level. Our country has already organized the Chinese Academy of Sciences to exploit the technology development roadmap for every major areas of China from now to 2050. 2) Industry level. The research of Guangdong province is most representativeness. By the end of 2012, Guangdong province had exploited more than 40 industry technology roadmaps, and published nearly 20 monographs. The doctoral theses of technology roadmap that can be inquired are mainly about the industry technology roadmap (Meng, 2009; Zhang, 2010) [10] [11]. 3) Theoretical research level. The writing "The theory and exploitation of industry technology roadmap" wrote by Zeng and Sun (2007) impacted most significantly and its method for the exploitation of industry technology roadmap has been used in more than 20 provincial regions and brought significant social benefit [12]. However, from wide view of the domestic research results, the literature about the study of the problems of the exploitation process of industry technology roadmap is rare, only the following a few.

Huang et al. (2007) argued that to exploit the industry technology roadmap should regard these aspects: 1) The popular advantages and the geographic advantages of the regions; 2) The tendency of the policies made by the government in future; 3) The choice of the method of the exploitation of technology roadmap based on the feature of the regions; 4) The development feature of the regional industry and the development tendency of that; 5) The situation, characteristic and development potential of the industry in the region and country. Meanwhile, they regarded above aspects and combined the regional feature of Ningbo to determine the sequence of the exploitation of automobile parts industry technology roadmap of Ningbo. At last, they pointed out that to exploit the industry technology roadmap based on the regional feature should regard many factors and that is an issue remained to study and discuss in depth [13]. Tan et al. (2007) combined technology roadmap and real option to build a framework of emerging technology choice and commented the industry innovation model of technology roadmap [14] [15]. Lie (2009) researched the R\&D risk of the enterprise and the control of the risk based on roadmap [16]. Liu et al. (2010) investigated the established method and system of the knowledge network synergy of technology roadmap oriented [17]. Gao (2011) pointed out that when we were defining the industry boundaries of the regional industry technology roadmap, we should not only to follow the principle of that, but also regard the characteristic of the regional industry. [18] Tong (2012) argued that the seminar of industry technology roadmap was a HWME system, we should use the approach proposed by Qian Xuesen to handle OCGS - an integration approach that from qualitative to quantitative - and built an industry technology roadmap consensus system emerging model at last [19].

Although the domestic and foreign scholars investigated the problems exist in the exploitation process of industry technology roadmap, they just investigated several problems. Thus it may hard to grasp the whole process of the exploitation of industry technology roadmap in the general. Base on this reason, this paper try to systematically analyze several problems exist in the exploitation of domestic industry technology roadmap to improve the efficiency of the roadmap as a whole.

\section{Several Problem Analyses of the Exploitation Process of Domestic Industry Technology Roadmap}

\subsection{The Top-Level Is Not Designed Well before Exploiting the Industry Technology Roadmap and the Definition of the Research Boundaries Is Unreasonable}

Through the research and investigation, the author found that some provinces and regions which exploited the roadmap in our country, especially the local government who was the organizer didn't know that the core part of the exploitation of industry technology roadmap was the definition of the industrial research boundaries and they took it for granted that industry technology roadmap should be an integration of the key common technologies of the whole industrial chain, resulted in huge waste of manpower, material resource and money. They can't know the industry technological base and the requirement of the future market, and they can't distinguish technical research priorities. Thus, they delayed the industrial key common technological difficulties which was urgent in local, resulted in the industry technology roadmap they published was unpractical, that was difficult to 
guide the development of local industries.

Therefore, in the preparation stage of the exploitation of industry technology roadmap, the dominant constitutor or the decision maker must fully understand the development foundation, development tendency and development requirement of the local industries. Meanwhile, they must fully understand how to exploit the roadmap and how to help the local industries make the investment decisions. In a manner speaking, the exhaustive investigation and the thorough top-level design are the foundation for the successful exploitation of industry technology roadmap.

\subsection{The Innovation Talents of the Related Areas of the Industry Did Brainstorming Deficiently and Didn't Guarantee to Participate Sustainable}

For saving expenditure or accelerating the process, the constitutors of industry technology roadmap didn't do their best to invite the industry professionals to participate the seminars for clarifying the market requirement, analyzing the industrial target, determining the industry barriers and locking the research requirement. They based on their experience or subjective feelings to invite choose the participants of the exploitation of roadmap. Because some experts were familiar with their research areas but unfamiliar with other areas, resulted in that the idea proposed by these experts were more subjectivity. If the participant range is limited, it is hard to achieve good result which accords with the law of industry development or the objective reality by brainstorming or other methods, which resulted in that it is hard to make the industry technology roadmap become the decision reference which supports the development of local industries.

The industry technology roadmap reflects the opinions of the future of some industries and the methods to make that come true. The roadmap is a basic tool of technology management and R\&D management. Due to the roadmap has become practical tool, the difference of the users' level and experience results in the difference of the patterns and use skills of the roadmap. Thus, we should gathers innovation talents from different fields included administration, industry, study, research and use as possible as we can, and ensure that they will abidingly participate the exploitation of industry technology roadmap, in order to integrate all sorts of views vastly and unify these views to an expected target which satisfies the requirement of the users from every level and becomes the scientific decision that supports the development of local industries.

\subsection{The Method for Exploiting Industry Technology Roadmap Was Single, the Stockholders Did Not Participate the Exploitation Well}

The organizers of industry technology roadmap thought that the industry technology roadmap can not only forecast the key common technology bottleneck of the industry development, but also provide support for tackling key problem of the key common technology, thus they thought the industry technology roadmap should be used by the government or industry association. Therefore, when the organizers organized the exploitation of industry technology roadmap, they would deservedly invite the people from government sector or industry association, but the number of participants who were the experts from university, research institution and enterprise was limited, that result in the information of the four seminars of the exploitation process is limited and the participants knew little about the base of the industry technology development. Thus, the enterprises couldn't combine the achievement of the research of industry technology roadmap effectively. It cause a result that though the local industries exploited technology roadmap, the enterprises - the cells of the industries, especially the UMKM couldn't resonate with the roadmap, the key common technology bottleneck still couldn't be broken through, the industry still lacked development target, development orientation and didn't know what to do.

Horizontality, the roadmap combines the target, resource and market vividly, effectively, and defines their relation and attribution. Verticality, it can unify the past, present and future to not only describe the current situation, but also forecast the future. Therefore, to use various expert-based approaches, workshop-based approaches and computer-based approaches [6] for promoting the practical efficiency can better intensify the degree of participation of the stockholders and vary the participation ways.

\subsection{A Thought That It Doesn’t Need to Update the Industry Technology Roadmap after Exploitation}

The starting point of the exploitation of industry technology roadmap is depended on the market requirement of 
a given period, especially of the period of the exploitation of technology roadmap. The subsequent market target, industry barriers and $R \& D$ requirement are determined by the discussion based on that the market requirement has been clarified. Because the exploitation of industry technology roadmap need a process which generates a time-lag between the start day and the publish day. According to the author's experience of exploiting industry technology roadmap, we know that the time-lag is about one to two years. The society changes every minute, various products appear one by one and the market requirement varies at any moment, consequently, the prediction of the roadmap for the tendency of future development of industry technology will deviate the fact in 3 to 5 years. We should revise and update the roadmap in time, or the guiding function of industry technology roadmap will weaken.

Ex-consultant of the American president on science and technology, Branscomb, defined the technology roadmap as "the consensus about the technology foreground, which is based on the science knowledge and forecast". Today, under the environment of that science and technology develop quicker and quicker and the competition is increasingly fierce, the risk of the choice for technology of the industry development is increasing. Therefore, we should update the roadmap in batches depend on the related factors that the scale of the related industries development in local region, the effect of the radiation and driving unction and the importance for the society, to clarify the questions such as "Where do we go?", "Where are we?" and "How can we get there?", to contribute to a better local industry development planning, consequently to realize the transformation from industry technology to market.

\subsection{A Thought That Industry Technology Roadmap Is a Soft Science Issue Which Can Be Exploited by Anyone}

Through the interview, the author found that some governmental organizers who organized the exploitation of industry technology roadmap thought that industry technology roadmap was a soft science that everyone with soft science research ability could exploit it well. Furthermore, some persons thought that no matter how many roadmaps for different industries, all of them could be exploited by an institution with soft science research ability.

They hardly realized that the exploitation of industry technology roadmap needs the experts, entrepreneurs and scholars from different areas, corresponding to different industries. Only they know about the industrial market requirement, industrial technology development tendency and the industrial frontier domains, the participants who understand the key point of the breakthrough for the common key technology can communicate and discuss sufficiently to exploit a practical industry technology roadmap.

\subsection{The Results of Key Common Technology Wasn't Outstanding, the Innovation Dynamics of Business Model Was Needed to Be Enhanced}

If the exploitation of industry technology roadmap is for clarifying several key common technology bottlenecks in the industrial chain of related industries, finding the breakthrough of them and helping to grasp the important technology areas of the future industry development, then the roadmap can just help the government, industry associations or other research institutions to make the technology breakthrough and do R\&D activities, but not serve the whole process of the technology innovation ${ }^{3}$. Because at this stage, the industry technology roadmap exploited by all over the country can just help to integrate the related innovation resource, perfect existing industry innovation system and capture the key common technology of related industry through enhancing the technology innovation dynamics. However, there is limited number of the technology that can be realized industrialization after breaking through, convert to products with intellectual property and occupy certainly market share. Meanwhile, because the guiding thoughts of the earlier stage of the exploitation did not require the roadmap to promote economic development, but require the roadmap to condense the high-grade or frontier fundamental knowledge, and that leads to a dim future of the industrialization of these technologies. If the industry technology roadmap is just for clarifying the key common technology, or capturing key common technology,

${ }^{3}$ From the perspective of scientific management to define the technology innovation, the current international definition tends to adopt that define by the research department of the library of U.S. Congress-The technology innovation is a process from the generation of the idea of new product or new process to the market application. To see details, Huo Fuguang, Lin Jianxin et al. "The compared research of Chinese and American innovation mechanism-and discuss the strategy for improving the innovation mechanism of Guangdong, Hong Kong and Macao", Beijing, People's Publishing House, 2004. 
but not creating new commercial model to make technology breakthrough become a part of innovation to realize the value of roadmap, then the mission of the industry technology roadmap still needs to be completed.

To complete the mission, we must change the guiding thoughts for the exploitation of roadmap, confirm the aim that to solve the problem that the separation of the science \& technology and economy, and create new commercial model strongly. The innovation of the commercial model mainly perform in five reconstruction, reconstruction of value proposition, reconstruction of operation system, reconstruction of profit model, reconstruction of key resource and abilities, reconstruction of cash flow structure. To make the guiding function of the industry technology roadmap efficiency, we must know that the announcement of industry technology roadmap is just the beginning to put the road into effect, the deficiencies of system, mechanism, talents and organization structure found in the process of exploiting roadmap, especially the deficiencies of innovation ability are the important points that need to be modified and completed when we are creating new commercial model. At the same time, we need to integrate these source factors such as macro politics, macro economy and culture into a unitive analysis framework to optimize the key points and orientation of the innovation of commercial model. In addition, the key point of creating new commercial model is that to set the key enterprises as examples to impel the combination of science \&technology and economy to solve the separation of science \& technology and economy. We should make the technology roadmap not only support the industry planning, but also support the product planning and other commercial functions include the development of new business opportunities, the distribution of resource, the formulation of commercial strategy and planning.

\subsection{Did Not Form System Thinking and Did Not Integrate the Industry Technology Roadmap as an Organic System Includes Talents, Technologies, Equipment and Money in the Process of Exploitation}

Most people think that the industry technology roadmap is just as its name implies, is to clarify the industry technology chain, ensure the sequence to strive to make the breakthrough of industry key common technology, and then the mission of roadmap is finished. Because of this misunderstanding, many regions spent the same project expenditure but the final result of the exploitation of roadmap just about the level of technology chain.

However, to sort out the key common technology of the industry chain can associate the technical equipment, technical talents and capitals, results in an innovation network topology whose main chain is industry technology chain and auxiliary chains is equipment chain, talent chain and capital chain. That can help us to purposefully choose the reliable innovation resource in the process of solving key technology problems. Subsequently we will get double the result by doing half the work.

\section{The Implications for Science \& Technology Management of the Local Government}

\subsection{To Form the Science \& Technology Management Thought Based on the Local Demand}

"Local demand" requires that the work of science and technology management should be developed based on the local economy and society or based on the actual demands of the aspects of the industrial and local development, and requires us to execute the science and technology management in a planned way, to arrange science and technology planning project in due time, to innovate the management mechanism and guide the R\&D activities based on the market and social demand.

Based on the development demand of local industries and enterprises, industry technology roadmap has already formed technology $R \& D$ barriers of recent, medium and long term in some areas. On the basis of local scientific research strength and local industry development, the roadmap proposes recent, medium and long term targets that impel the breakthrough of industry technologies, and realizes the targets with the science \& technology innovation resource through the science $\&$ technology planning projects to realize the transformation of research result, to solve the separation of science \& technology and economy, to form the demand logic and to do what the local region needs. To abandon the supply logic defects, it had the science $\&$ technology inventions or innovations first and then sought the application of these achievements for the development of economy and society, and then it could observably promote the relation between the science \& technology development and economy and society.

The science \& technology management idea guided by local demand is a management idea based on complete 
demand investigation and research, and demand analysis. It can definitely set up the science \& technology work theme, plan the distribution of the science \& technology innovation resource to make technological breakthrough, and then realize industrialization driven by market demand. On the one hand, it can avoid the defects of low level of the industrialization of research result. On the other hand, it can overcome the inertia of creating new commercial model under unidentified market demand. The science \& technology management idea guided by local demand not only follows the law of science \& technology development, but also follows the rules of the market economy, which can promote the development of local economy and society significantly.

\subsection{To Form System Thinking and to Optimize the Management Process Depend on the Key Points of Different Links}

In the program for tackling key problems of each process of industry technology roadmap, it has not only the research of advanced technology, but also the research of application and development, and then realizes the convert of research results. According to different levels, to carry on the classified management and optimize management process seems more important.

In the local government science \& technology management work, the governmental research institutions always undertake the mission of fundamental research or advanced technology research. However, because of the lack of expenditure, they also work on technology development to acquire extra expenditure, which makes the resource distributed to the fundamental research reduce, which results in the research quality deteriorates, and then the technology development of enterprises will lack driving force because of the reduce of support from the fundamental research or advanced technology research. At last, it will result in a situation that the working process of the research activity converts to research result and the research result converting to productivity may be not so reasonable.

Therefore, the science \& technology management of local government needs to intensify the top-level design, to form system thinking, direct at the key points of different links of the key, difficult, focus issue of local development, to coordinate the resource of natural science and social science areas, to optimize the management process. If the government wants to increase the investment in science and technology, it should not only pay for the expenditure of fundamental research or advanced research, but also invest a lot of expenditure to the applied research, development research and soft science research. The thing need to be noticed is that local government should strengthen the construction of innovation environment in the link that the governmental research institutions take charge of the fundamental research or advanced technology research. Such as direct at the special, planning requirement of the country or the superior government department, to strengthen the platform of research condition, to promote the talent introduction and cultivation, to build an innovation atmosphere that encourage to explore, tolerate failure. In the link of applied research, local government needs to focus on the layout of the development of science \& technology service industries such as research industry and push it depend on the key science \& technology demand of the local economy and society development base on the related planning of country or superior government. In the link of development research and experimental research, the focal point of the science \& technology management work of local government should be creating a good technical service environment, improving the legal system and local innovation system to benefit the transformation and industrialization of the research results, and providing support for the development of local pillar industries, characteristic industries, competitive industries, high-tech industries and strategic emerging industries. In the link of soft science research, the key point of the science \& technology management work of local government should be creating a good academic atmosphere, building a market for ideas that schools of thoughts contend and flowers bloom, so that the development of local economy and society would be better promoted.

\subsection{To Conduct the Participants of Industry-University-Research Cooperation to Establish and Improve the Industry-University-Research Cooperation Mechanism of Sustainable Development}

The scientificity of exploitation of industry technology roadmap is positive related to the construction and range of the participants. If it can establish a good industry-university-research cooperation mechanism, optimize and integrate the innovation talents from each field, and ensure them to take part in the whole process of the exploitation of roadmap, so that the roadmap will have more authority and guidance.

In a similar way, for ensuring the science \& technology management work of local government to be suc- 
cessfully carried out and ensuring the allocative ability of innovation resource to be strengthened, local government needs to conduct the participants of industry-university-research cooperation to establish and improve an operating mechanism with the combination of competition and cooperation, the combination of efficiency and task, the combination of incentives and orderly. It is mainly embodied that, first, the government should publish the preferential policy for the industry-university-research cooperation associations, build a dynamic mechanism of the industry-university-research cooperation, build and improve the dynamic mechanism with multi-lateral cooperation that driven by technology, pulled by market and motivated by policy, so that build an effective vitality mechanism that centrally coordinated by the local science \& technology management department but with great flexibility [20]. Second is to build the choice mechanism of the industry-university-research cooperation. That is the government should choose the cooperation or not and the cooperators depends on the development demand on the basis of awareness and comparison to choose the niche partners for the future development of the local economy and society. Third is to build the legal mechanism of the industry-university-research cooperation. As a compulsory social regulation, the law can facilitate, protect and prevent the industry-university-research cooperation. Thus, if the local government can legislate for the industry-university-research cooperation, or be a indemnity or of the contract signing for the related benefit of the participants of the industry-university-research cooperation, so that it can build a complete, reasonable and lawful legal mechanism for the participants. The last is to build the evaluation mechanism for the industry-university-research cooperation. The local government needs to integrate the power of each party to construct an evaluation index system, use scientific evaluation methodology and assessment routine to evaluate the contribution of the participants for the cooperative cause, and then determines the industry-university-research organizations maintain or remove depend on the evaluating results.

\section{References}

[1] Tong, R. and Li, C.D. (2011) The Discipline Position of Technology Roadmapping Research and Its Theory and Practice Review at Home and Abroad. Forum on Science and Technology in China, 3, 142-145.

[2] Kostoff, R.N. and Schaller, R.R. (2001) Science and Technology Roadmaps. IEEE Transactions on Engineering Management, 48, 132-143. http://dx.doi.org/10.1109/17.922473

[3] Gerdsri, N. and Kocaoglu, D.F. (2007) Applying the Analytic Hierarchy Process (AHP) to Build a Strategic Framework for Technology Roadmapping. Mathematical and Computer Modelling, 46, 1071-1080. http://dx.doi.org/10.1016/j.mcm.2007.03.015

[4] Lee, S., Lee, S., Seol, H. and Park, Y. (2008) Using Patent Information for Designing New Product and Technology: Keyword Based Technology Roadmapping. R\&D Management, 38, 169-188.

[5] Yoon, B., Phaal, R. and Probert, D. (2008) Morphology Analysis for Technology Roadmapping: Application of Text Mining. $R \& D$ Management, 38, 51-68.

[6] Liu, X.W. and Ke, C.X. (2006) The Research on Present Situation of Drawing Method for Technology Roadmap Abroad. Research Report of The Main Library at National Science Library of Chinese Academy of Sciences.

[7] Science and Technology and Intellectual Property Office of Panzhihua. The Theory of Technology Roadmap. http://www.panzhihua.gov.cn/ztzl/ftzd-kjzk/cyzc/jslxt/132996.shtml

[8] Li, X.F., Tong, Y.H. and Tan, Y. (2004) Technology Roadmap-A New Technology Management Tool. Studies in Science of Science, $\mathbf{S 1}, 89-74$.

[9] Li, X.F., Tong, Y.H. and Tan, Y. (2005) Technology Roadmap and Thought of Technology Roadmap. Science of Science and Management of $S \& T, \mathbf{8}, 26-28,59$.

[10] Meng, H.H. (2009) Research of Industry Technology Roadmap. Doctoral Dissertation of University of Science and Technology of China.

[11] Zhang, Y. (2010) Research of Industry Technology Roadmap of Large Heavy Duty Numerical Control Machine Tools Industry in Hubei. Doctoral Dissertation, Huazhong University of Science \& Technology, Wuhan.

[12] Zeng, L. and Sun, Y.M. (2007) The Principal and Exploitation of Industry Technology Roadmap. Press of SCUT, Guangzhou.

[13] Huang, H.B., Tan, Y., Liu, J., He, H.B. and Li, H.L. (2007) Roadmap-Drawing for Local Industrial Development. Journal of Ningbo University (NSEE), 3, 333-336.

[14] Tan, Y. and Huang, Y.L. (2007) The Model Research of Emerging Technology Planning and Choice Based on Process. Science and Technology Management Research, 8, 5-8.

[15] Tan, Y., Tong, Y.H. and Li, X.F. (2007) The Industrial Innovation Model Based on Technology Roadmap: A Selective 
Literature Review. R\&D Management, 19, 23-30.

[16] Lie, M.Z. (2009) The Research of Enterprise R\&D Risk Control Based on Technology Roadmap. Master's Dissertation, Wuhan University of Technology, Wuhan.

[17] Liu, J., Chen, J.X., Gu, X.J., Hu, H.J., Dai, F. and Ji, Y.J. (2009) Knowledge Network guided by Technology Roadmap. Journal of Zhejiang University (Engineering Science), 43, 2218-2224.

[18] Gao, Z.X. (2011) Definition of Industry Boundaries and Scope in Regional Industrial Technology Roadmap. Science and Technology Management Research, 16, 120-122.

[19] Tong, R. (2012) Industry Technology Roadmapping Research Based on Meta-Synthesis Methodology. Science \& Technology Progress and Policy, 1, 69-73.

[20] Huo, F.G. and Chen, J.X. (2004) Comparative Study of Innovation Mechanism in China and US. People's Publishing House, Beijing. 